$\xi=-1$

\title{
The Development of Athlete Performance Capabilities Index (APCI) Model for Male U12 Player Selection using Multivariate Analysis
}

\author{
Mohamad Razali Abdullah ${ }^{1,2 *}$, Hafizan Juahir ${ }^{2}$, N. Mohamad Shukri ${ }^{1}$, N.A. Fuat ${ }^{1}$, N.A. Mohd Ros ${ }^{1}$, F. N. Shukri ${ }^{1}$, \\ N. S. Abd Halim ${ }^{1}$, Siti Musliha Mat-Rasid ${ }^{2}$, Rabiu Muazu Musa ${ }^{1}$, Ahmad Bisyri Husin Musawi Maliki ${ }^{1}$, Norlaila \\ Azura Kosni ${ }^{1}$, Mohd Syaiful Nizam Abu Hassan', Mohd Khairi Zawi ${ }^{3}$, Vijayamurugan Eswaramoorthi ${ }^{4}$ \\ ${ }^{I}$ Faculty of Applied Social Sciences, Universiti Sultan Zainal Abidin, Terengganu, Malaysia \\ ${ }^{2}$ East Coast Environmental Research Institute (ESERI), Universiti Sultan Zainal Abidin, Terengganu, Malaysia \\ ${ }^{3}$ National Sports Institute, Bukit Jalil, Kuala Lumpur, Malaysia \\ ${ }^{4}$ Faculty of Health Science, Universiti Sultan Zainal Abidin, Terengganu, Malaysia \\ *Corresponding author Email: razaliabdullah@unisza.edu.my
}

\begin{abstract}
This study develops an Athlete Performance Capabilities Index (APCI) model using multivariate analysis for selecting the best player of under twelve (U12). Measurement of anthropometrics and physical fitness were evaluated among 178 male players aged $12 \pm 0.52$ years. Factor score derived by Principal Component Analysis were used to obtain a model for APCI and Discriminant Analysis (DA) were conducted to validate the correctness of group classification by APCI. Result was found two factors with eigenvalues greater than 1 were extracted which accounted for $62.00 \%$ of the variations present in the original variables. The two factors were used to obtain the factor score coefficients explained by $35.72 \%$ and $26.67 \%$ of the variations in athlete performance respectively. Factor 1 revealed high factor loading on fitness compared to Factor 2 as it was significantly related to anthropometrics. A model was obtained using standardized coefficient of factor 1 . Three clusters of performance were shaped in view by categorizing APCI $\geq 75 \%, 25 \% \leq \mathrm{APCI}<75 \%$ and APCI $<25 \%$ as high, moderate and low performance group respectively. Three discriminated variables out of thirteen variables were obtained using Forward and Backward stepwise mode of DA, which were weight, standing broad jump, and 40 meters' speed. Such variables were established as essential indicator for selecting the best player among male U12.
\end{abstract}

Keywords: Athlete performance model; Capabilities Index; Male U12 player; Multivariate analysis.

\section{Introduction}

The development of long-term athletes has been progressively planned and athletes are individuals identified as long-term athlete development (LTAD) also known as LTPD for long-term development of players or players' long-term development. LTAD has provided proper explanation on every stage of human development where every child has a right to get the best chance to engage in physical activity that can improve lifetime health; and for those with talent can get the best chance of success in sports. The development of an effective long-term athlete does not focus on short-term profits and early success alone, but the best athletic development is the health of lifelong athletes [1].

Many sports leaders have re-established sports development to contribute to the betterment of a better society, athlete's ethical development, and to provide a high quality experience for all societies. However, to achieve this goal, they must work diligently to link traditional, non-functional institutions and link sports and physical activities to other sectors of the modern society, such as education and health. This collaboration is needed to meet the demands of schools, clubs and teams to produce new talent in sports. In order to fulfill this desire, each of the athletes needs to engage in a sport [1].
This planning is needed as it is a specific practice to ensure the development of students in the field of sports can be enhanced. Hence, schools that conduct sporting competition among students will ensure students through the optimum development process in their athletic career. This is because in order to gain a continuous breakthrough in a career, a player must start that step by doing continuous training and maintaining good performance for a long time. There are no shortcuts to success in sports provision without involving all stakeholders [2].

In addition, the youth sports program has been recognized at the highest level so that youth development has a positive impact. This can help all young athletes learn about themselves as well as develop life skills [3]. The sports domain has been recognized as a good context. This is to develop the life skills of every athlete and to promote positive youth development. Positive developments in each student can be cultivated in the field of sports by learning the various skills in life, cultivating pure values in themselves and applying the attitude of always doing the welfare of their life's performance in evolving throughout life [4].

In recent decades, talent recognition and athlete development among students have been gaining popularity, though there is a lack of consensus. This lack is related to how talent can be identified and there is no uniform theoretical framework to identify the 
talent of a child [3]. With this, it can create more talented and quality children in sports.

The introduction of talent and finding the most effective method of sports is a tough problem and is a complicated matter to solve [5]. There are many models that define talents worldwide are supported by a concerted talent conception and are unlikely to be like them $[6,7]$. Hence, problems often arise in the dependence on genetically-carried out achievement measures by emphasizing the selection of 'improper' talented individuals rather than development and monitoring of potential. Such concepts provide a more accurate description of the important factors influencing talent and therefore a better ability to predict future star performers. Finally, a theoretically driven, multidisciplinary model of talent identification and development will be described which is currently being piloted in Scotland.

Related study had identified and develop potential and talented athlete in sport team like football which complex in nature bears anthropometric evidence, physiological, psychological, technical and perception towards performance [8]. Recent approach however has proposed development of performance index as a tool for identifying best player $[9,10]$. The application of advanced statistical and multidimensional analysis became vital nowadays to measure athlete performance more objective (Abdullah et. al, 2017). Hence, this study aims to develop an Athlete Performance Capabilities Index (APCI) model by using factor scores derived from PCA to predict performance of male athlete under 12 .

\section{Materials and Methods}

\subsection{Participants}

The anthropometric measurement and physical test data in this study were obtained from 178 male students aged $12 \pm 0.29$ years old from primary schools in several areas in Terengganu, Malaysia. All the participants were informed and their parents are required to fill out a consent form to participate in a sports development program.

\subsection{Testing Procedure}

They were tested on four anthropometrics component (weight, height, sitting height and arm span); and nine motor subscales included power, flexibility, speed and endurance.

\subsubsection{Weight}

To measure weight, make sure the scale of the bath is placed on a flat surface and stable position using the correct technique when weighting. When weight gain, the player should stand in the centre of the platform without moving the limbs up to the scale of the bath to properly weight out the student's weight.

\subsubsection{Height}

Player were stand up and close their back to the wall. Then, using a pencil, a conductor will indicate where the highest point is at the top of the head on the wall surface. Then using a measuring tape, they need to measure the distance from the point they mark on the dinging down to the bottom of the floor.

\subsubsection{Sitting height}

Measuring sitting height is a measurement of the distance from the highest point on the head to the base sitting surface. Player were sits with both feet on the floor, lower back and shoulders against the wall and looking straight ahead.

\subsubsection{Arm span}

The player standing straight to the wall and stretch both arms from the body with lean against the wall. Their arm and body needed to be measured 90 degree's angle. The distance from the tip of the middle finger to the right to the tip of the middle finger of the left hand were measured using measuring tape. This gives precise measurements for arm reach.

\subsubsection{Standing Broad Jump}

The player was standing behind the lines marked with the legs by swinging the arm and flexing the knee forward. Then player was jumping as far as possible according to their ability and landing both feet without falling backward. Equipment used is the tape measure to measure jumping distance and commercial long jump mat.

\subsubsection{Vertical Jump}

Players were facing the wall that smooth, dark with a second flat foot in the floor and toe touch wall. Then students achieve as high as may be with both hands and marking in a wall (or board jump / wooden wall fitted) with a piece of chalk or chalk tray. Holding position jump is wanted with side choice to-wall, students jump as high as may be and make different signs on top jump. Score jump vertical is the difference between two prints (recorded in centimetres).

\subsubsection{0 meter, 20 meter and 40 meters' speed}

$10,20,40$ meters' run were conducted in this study to measure student's ability to accelerate, speed endurance and maximum running speed, depending on the distance run. This speed tests were typically officiated using stopwatches, measuring tape or marked track, cone markers. The test involves a run with maximum acceleration according to the specified 10, 20 and 40 meters' distance, with time recording. The starting position were standardized, starting from a stationary position with one foot behind the starting line and recording time with a stopwatch at the finish line.

\subsubsection{Sit and Reach}

Sit and reach test procedure involving sitting on the floor with the feet and straightening the feet forward without wearing shoes. Half feet should be flat on the box and both knees should be locked and pressed flat to the floor and can be assisted by the tester. After all, students need to reach forward and keep their hands on the same level after the practice is achieved. Need to ensure no simultaneous movement. The equipment used is the reach box and positioning method.

\subsubsection{Max Push Up}

The procedure of male push up in this study used the standard "military style" push up position with only the hands and the toes touching the floor in the starting position. To do this, player put their hands on either side of the chest and keep their back straight then lower the chest down towards the floor, until either the elbows are at right angles or the chest touches the ground. Players do as many push ups as possible until exhaustion. The total number of push ups performed are recorded.

\subsubsection{Min Sit Up}

This test is to measure the strength and endurance of the abdominals and hip-flexor muscles. For the starting, students lie on a cushioned floor with student's knees bent at approximately right angles and with two feet flat on the ground. Student's hands should be resting on chest. Technique, students squeeze their stomach then push back flat and raise high enough for students' hands to slide along thighs to touch the tops of students knees. Students cannot pull with their neck or head and keep lower back on the floor. Then, return to the starting position.

\subsubsection{Predicted VO2 max}


The test evaluates an individual's aerobic endurance fitness. The equipment required were flat and non-slip surface, cones, measuring tape and recording sheets. Two lines of 20 meters apart was marked by cones. Player start with their feet behind the line, and start running when directed. They continue to run between two rows, and turn away when signal by the recorded beep sound. After every minute or so, the pace gets faster. If the line cannot be reached in time, the students should run to the line turn and try to pursue speed in 2 'beeps'. This test is stopped if the subject fails to pursue the pace within the two ends.

\subsection{Statistical Analysis}

\subsubsection{Pre-processing data}

A matrix set of male group contain 2314 matrices data (13 variables $\times 178$ players) were computed in this study. The total missing data in the matrices are very small $(\sim 3 \%)$ compared to the overall data recorded. Hence, for the data analysis screening, the nearest neighbor method was applied using XLSTAT 2014 add-in software [11]. This method examines the distance between each point and the closest point to it. The nearest neighbor method is the simplest methods, where the end points of the gaps are used as estimates of all missing values.

\subsubsection{Principal Component Analysis (PCA)}

PCA is a common technique for finding patterns in data of high dimension $[12,13]$. The idea behind of PCA is by which numbers of correlated variables are transformed into a smaller number of uncorrelated variables. The previous study applied PCA to provide indications for race walkers' classification and identified potentially important technical differences between higher and lowers skilled athletes [13]. Kaiser-Meyer-Olkin (KMO) measure of sampling adequacy was used in the study. It is important to test if the sample size was good and big enough for principal component analysis (PCA). If the results of correlation matrix are an identity matrix, its means that PCA is not great and appropriate. If the data were appropriate, was used to extract the factors. The extraction of the factors was done by calculate the eigenvalues of the correlation matrix. The standardized coefficient by selected factor were used to develop athlete performance model.

\subsubsection{Discriminant Analysis (DA)}

DA was applied in this study to specify whether the groups vary with respect to the mean of a variable and to utilize that variable to expect group membership. Three groups for relative performance pattern (three sampling groups including high performance group moderate performance group, and low performance group) were assigned by proposed Athlete Performance Capabilities Index. The DA was put into the raw data using the standard, forward stepwise, and backward stepwise methods [11]. These were used to construct DFs to evaluate relative performance variations in the anthropometric and fitness performance. The relative performances of the athletes were the dependent variables that is collected while all the components evaluated are independent variables. Likewise, in forward stepwise mode, variables are calculated in step by step starting with a very important variable until no significant changes are obtained. In the backward stepwise mode, the variables are removed step by step starting with a less important variable until no significant change is obtained.

\section{Results and Discussion}

Table 1 presents the descriptive statistic of anthropometric measurement and fitness included mean and standard deviation. Value of minimum and maximum also were recorded in the table.
Table 1: Descriptive statistics of variables among male U12 player

\begin{tabular}{|c|c|c|c|c|}
\hline Variables & Min & Max & Mean & Std. Dev. \\
\hline Weight (kg) & 24.0 & 66.0 & 36.4 & 9.6 \\
\hline Height (cm) & 123.4 & 159.1 & 141.8 & 6.5 \\
\hline Sitting Height (cm) & 61.2 & 80.2 & 71.8 & 3.7 \\
\hline Armspan (cm) & 123.0 & 165.8 & 143.1 & 7.9 \\
\hline Standing Broad Jump (cm) & 96.0 & 215.0 & 151.8 & 20.3 \\
\hline 10 Meter Run (s) & 1.62 & 2.65 & 2.16 & 0.20 \\
\hline 20 Meter Run (s) & 3.00 & 4.84 & 3.83 & 0.31 \\
\hline 40 Meter Run (s) & 5.27 & 9.35 & 7.22 & 0.65 \\
\hline Vertical Jump (cm) & 25.0 & 53.0 & 36.2 & 5.3 \\
\hline Sit and Reach (cm) & 14.5 & 41.0 & 28.0 & 4.6 \\
\hline Max Push Up & 1 & 37 & 14 & 8 \\
\hline 1 Min Sit Up & 1 & 31 & 12 & 7 \\
\hline VO $_{2}$ Max (ml/kg/min) & 15.40 & 44.40 & 30.51 & 6.72 \\
\hline
\end{tabular}

Table 2 showed the coefficient of correlations between variables involved in this study. Positive and significant $(\mathrm{P}<0.05)$ correlations were obtained for sitting height and weight $(\mathrm{r}=0.071)$, sitting height and height $(\mathrm{r}=0.84)$, armspan and height $(\mathrm{r}=0.91)$, armspan and sitting height $(r=0.76), 20$ meter run and 10 meter run $(r=0.82), 40$ meter run and 10 meter run $(r=0.86)$ and 40 meter run and 20 meter run $(r=0.91)$.

Table 2: Coefficient of correlations between variables involved in this study

\begin{tabular}{|c|c|c|c|c|c|c|c|}
\hline Variables & $i^{\infty 00}$ & I0 & $\vec{E}$ & \& & $\overrightarrow{0}$ & 5 & $\underset{\sim}{\stackrel{\alpha}{x}}$ \\
\hline $\mathrm{Wg}$ & 1 & & & & & & \\
\hline $\mathrm{Hg}$ & 0.65 & 1 & & & & & \\
\hline SH & 0.71 & 0.84 & 1 & & & & \\
\hline AS & 0.63 & 0.91 & 0.76 & 1 & & & \\
\hline SBJ & -0.38 & 0.01 & -0.02 & 0.01 & 1 & & \\
\hline $\mathrm{VJ}$ & -0.16 & 0.2 & 0.16 & 0.21 & 0.48 & 1 & \\
\hline SAR & 0.11 & 0.12 & 0.38 & 0.17 & 0.19 & 0.28 & 1 \\
\hline $10 \mathrm{MR}$ & 0.36 & -0.01 & 0.02 & -0.02 & -0.53 & -0.59 & -0.18 \\
\hline $20 \mathrm{MR}$ & 0.37 & -0.04 & 0.00 & -0.05 & -0.58 & -0.57 & -0.17 \\
\hline $40 \mathrm{MR}$ & 0.4 & -0.05 & 0.00 & -0.1 & -0.64 & -0.59 & -0.17 \\
\hline MPU & -0.33 & -0.21 & -0.18 & -0.17 & 0.33 & 0.3 & 0.17 \\
\hline $1 \mathrm{MSU}$ & -0.10 & 0.2 & 0.14 & 0.17 & 0.3 & 0.39 & 0.14 \\
\hline $\mathrm{VO}_{2} \mathrm{Max}$ & -0.48 & -0.15 & -0.21 & -0.15 & 0.5 & 0.26 & 0.00 \\
\hline Variables & $\sum_{\underline{O}}^{\varrho}$ & $\underset{\text { ¿ }}{\stackrel{N}{\Delta}}$ & $\sum_{\stackrel{f}{f}}^{\stackrel{f}{f}}$ & $\stackrel{\overrightarrow{2}}{\mathrm{z}}$ & $\sum_{2}^{D}$ & 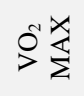 & \\
\hline $10 \mathrm{MR}$ & 1 & & & & & & \\
\hline $20 \mathrm{MR}$ & 0.82 & 1 & & & & & \\
\hline $40 \mathrm{MR}$ & 0.86 & 0.91 & 1 & & & & \\
\hline MPU & -0.24 & -0.28 & -0.26 & 1 & & & \\
\hline $1 \mathrm{MSU}$ & -0.34 & -0.41 & -0.40 & 0.04 & 1 & & \\
\hline $\mathrm{VO}_{2} \mathrm{Max}$ & -0.41 & -0.46 & -0.53 & 0.34 & 0.17 & 1 & \\
\hline
\end{tabular}

Values in bold is significant at the 0.05 level Note: Wg: Weight, $\mathrm{Hg}$ : height: SH: Sitting Height, Armspan: Armspan, SBJ: Standing Broad Jump, 10MR: 10 Meter Run, 20MR:20 Meter R1un, 40MR:40 Meter Run, VJ: Vertical Jump, SAR: Sit and Reach, MPU: Max Push Up, 1MSU: 1minute Sit Up

The summary of results of PCA is presented in Table 3. Two factors with eigenvalues greater than 1 were extracted which accounted for $62.40 \%$ of the variations present in the original variables. The first factor loaded heavily on standing broad jump (0.760), 10 meter run $(-0.86), 20$ meter run $(-0.90), 40$ meter run ($0.93)$, vertical jump (0.734) and predicted $\mathrm{VO}_{2 \max }(0.60)$ while the second factor loaded heavily on weight (0.79), height (0.79), sitting height (0.92) and armspan (0.91). Loading is the correlation between the original variables and the factors. The higher the factors loads are the better the variables are characterized by factors [14]. The unique contribution of each variable to the factor scores is presented in the factor score coefficient matrix. The factor score coefficient matrix shows the coefficients or weights by which variables were multiplied to obtain factor scores. 
Table 3: Summary of the results of Principle Component Analysis

\begin{tabular}{|c|c|c|c|c|}
\hline \multirow{2}{*}{ Variables } & \multicolumn{2}{|c|}{$\begin{array}{c}\text { Factor Score } \\
\text { Coefficients }\end{array}$} & \multicolumn{2}{c|}{$\begin{array}{c}\text { Rotated Factor } \\
\text { Loadings }\end{array}$} \\
\cline { 2 - 5 } & Factor 1 & Factor 2 & Factor 1 & Factor 2 \\
\hline $\mathrm{Wg}$ & -0.08 & 0.22 & -0.43 & 0.79 \\
\hline $\mathrm{Hg}$ & 0.03 & 0.27 & 0.07 & 0.93 \\
\hline $\mathrm{SH}$ & 0.02 & 0.26 & 0.03 & 0.92 \\
\hline $\mathrm{As}$ & 0.03 & 0.26 & 0.08 & 0.91 \\
\hline $\mathrm{SBJ}$ & 0.17 & -0.01 & 0.76 & -0.07 \\
\hline $10 \mathrm{MR}$ & -0.19 & -0.00 & -0.86 & 0.03 \\
\hline $20 \mathrm{MR}$ & -0.20 & -0.01 & -0.90 & 0.02 \\
\hline $40 \mathrm{MR}$ & -0.20 & -0.01 & -0.93 & 0.02 \\
\hline VJ & 0.16 & 0.07 & 0.73 & 0.20 \\
\hline SAR & 0.07 & 0.09 & 0.28 & 0.31 \\
\hline MPU & 0.09 & -0.07 & 0.42 & -0.27 \\
\hline $1 \mathrm{MSU}$ & 0.11 & 0.07 & 0.51 & 0.21 \\
\hline VO Max & 0.13 & -0.08 & 0.60 & -0.31 \\
\hline Eigenvalue & & & 4.64 & 3.47 \\
\hline Percentage of var. & & & 35.31 & 27.09 \\
\hline
\end{tabular}

Note: $\mathrm{Wg}=$ Weight, $\mathrm{Hg}=$ height: $\mathrm{SH}=$ Sitting Height, Armspan $=$ Armspan, SBJ = Standing Broad Jump, 10MR = 10 Meter Run, 20MR = 20 Meter Run, 40MR = 40 Meter Run, VJ = Vertical Jump, SAR = Sit and Reach, MPU = Max Push Up, 1MSU = 1 Minute Sit Up

The factor scores were used as independent variables to predict athlete performance based on anthropometric and fitness component. In practice, the use of factor scores as predictor variables is more reliable than interdependent variables in order to avoid multicollinearity [15]. Following procedure by previous study [16], the athlete performance model for APCI were obtained as shown in (1). Henceforth, to facilitate comparison between the respondent, APCI were presented the values in range from 0 and 100 using in (2).

$$
\begin{aligned}
\text { APCI }= & 1.7917-0.0087 \times \text { Wg }(\mathrm{kg})+0.0045 \times \mathrm{Hg}(\mathrm{cm}) \\
& +0.0054 \times \text { SH }(\mathrm{cm})+0.0039 \times \text { As }(\mathrm{cm}) \\
& +0.0082 \times \text { SBJ }(\mathrm{cm})+-0.9536 \times 10 \mathrm{MR}(\mathrm{s})
\end{aligned}
$$

$-0.6289 \times 20 \mathrm{MR}(\mathrm{s})-0.3134 \times 40 \mathrm{MR}(\mathrm{s})$

$+0.0311 \times$ VJ $(\mathrm{cm})+0.0147 \times$ SAR $(\mathrm{cm})$

$+0.0105 \times$ MPU $\left(\mathrm{No}_{2}\right)+0.0154 \times 1 \mathrm{MSU}\left(\mathrm{No}_{\mathrm{s}}\right)$

$+0.0190 \times \mathrm{VO}^{2} \mathrm{Max}(\mathrm{ml} / \mathrm{min} / \mathrm{kg})$

$\mathrm{APCI}_{\mathrm{m}}^{*}=\frac{\left(\mathrm{APCI}_{\mathrm{m}}-\mathrm{APCI}_{\mathrm{min}}\right)}{\operatorname{sann} *} \times 100$

where $\mathrm{APCI}_{\mathrm{m}}=$ final indicator value of the $\mathrm{m}^{\text {th }}$ player, $\mathrm{APCI}_{\mathrm{m}}=$ value of the indicator observed in the $\mathrm{m}^{\text {th }}$ player, $\mathrm{APCI} \mathrm{I}_{\max }=\max -$ imum indicator observed in the sample and $\mathrm{APCI}$ min $=$ minimum indicator observed in the sample.

Table 4: Category of APCI and number of respondent assigned by APCI

\begin{tabular}{|c|c|c|}
\hline APCI Category & Index & $\begin{array}{c}\text { Total } \\
\text { Player }\end{array}$ \\
\hline Low Performance group (LPG) & APCI $^{*}<25 \%$ & 8 \\
\hline $\begin{array}{c}\text { Moderate performance group } \\
\text { (MPG) }\end{array}$ & $25 \% 6$ APCI $^{*}<75 \% 6$ & 168 \\
\hline $\begin{array}{c}\text { High Performance group (HPG) } \\
\text { Total }\end{array}$ & APCI $^{*} \geq 75 \%$ & 2 \\
\hline \multicolumn{2}{|c|}{} & 178 \\
\hline
\end{tabular}

Table 5 shows the discriminant analysis conducted for the further analysis. HACA defines network is applied by DA to examine relative performance variation. The clusters act as the dependent variable, whereas relative performance parameters were treated as independent variables. To run DA, backward, standard stepwise, forward stepwise mode methods were selected. Classification accuracy use standard, backward step and forward step is $97.75 \%$ (three enablers' independent variable), $97.75 \%$ (three variables free) and $97.75 \%$ (three enablers' independent variable), respectively. The discriminated variables treated as essential indicator when selecting the best male player U12 were shown graphically

\begin{tabular}{|c|c|c|c|c|c|c|}
\hline & \multirow[b]{2}{*}{ Sampling Group } & \multirow[b]{2}{*}{$\underset{\delta}{\stackrel{1}{0}}$} & \multicolumn{3}{|c|}{ Group Assigned by DA } & \multirow[b]{2}{*}{ 퓽 } \\
\hline & & & LPG & MPG & HPG & \\
\hline \multirow{4}{*}{$\begin{array}{c}\text { Standard mode } \\
\text { (3 independent } \\
\text { variables) }\end{array}$} & LPG & $87.50 \%$ & 7 & 1 & 0 & 8 \\
\hline & MPG & $98.21 \%$ & 3 & 165 & 0 & 168 \\
\hline & HPG & $100.0 \%$ & 0 & 0 & 2 & 2 \\
\hline & Total & $97.75 \%$ & 10 & 166 & 2 & 178 \\
\hline \multirow{3}{*}{$\begin{array}{c}\text { Backward } \\
\text { stepwise } \\
\text { (3 independent } \\
\text { variables) }\end{array}$} & MPG & $98.21 \%$ & 3 & 165 & 0 & 168 \\
\hline & HPG & $100.0 \%$ & 0 & 0 & 2 & 2 \\
\hline & Total & $97.75 \%$ & 10 & 166 & 2 & 178 \\
\hline \multirow{4}{*}{$\begin{array}{c}\text { Forward } \\
\text { stepwise } \\
\text { (3 independent } \\
\text { variables) }\end{array}$} & LPG & $87.50 \%$ & 7 & 1 & 0 & 8 \\
\hline & MPG & $98.21 \%$ & 3 & 165 & 0 & 168 \\
\hline & HPG & $100.0 \%$ & 0 & 0 & 2 & 2 \\
\hline & Total & $97.75 \%$ & 10 & 166 & 2 & 178 \\
\hline
\end{tabular}
in Fig. 1.

Table 5: Classification matrix by DA for grouping of male U12

LPG: Low Performance Group; MPG: Medium Performance Group; HPG: High Performance Group; DA: Discriminant Analysis

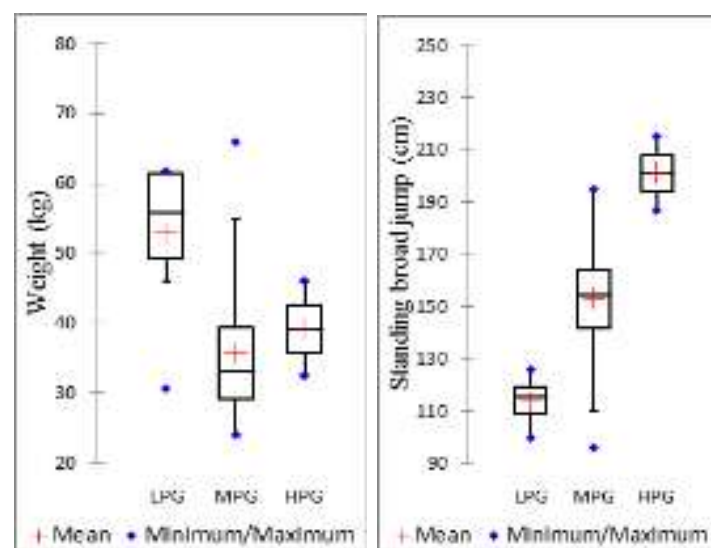

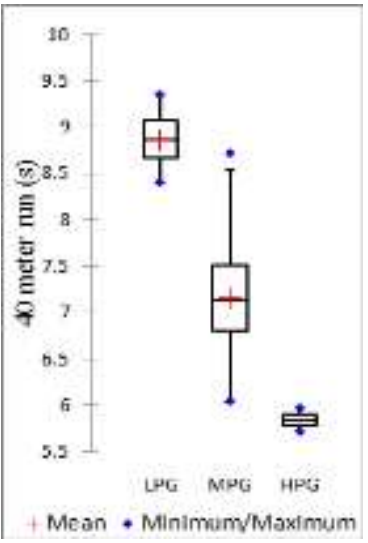

Fig. 1: Box and whisker plot of essential indicator for selecting the best male player U12 
The result obtained from the current study implies that weight, height, sitting height, armspan, 10 meter run, 20 meter run, 40 meter run, predicted $\mathrm{VO}_{2 \max }$ and sit and reach were found to be the most significant variable for identifying talent in sports. Over all, anthropometric and physical fitness were contributed high variation regarding the performance recognized to the sedentary youth. The finding of first component from PCA result revealed physical fitness of speed test as major physical fitness needed to be taken into account in athlete selection. In practical terms, it refers to the ability to move the body as quickly as possible over a set distance. The finding from first component also reveals that the male secondary pupils are attributable to high capacity in cardiovascular endurance $\left(\mathrm{VO}_{2} \max \right)$. This result is similar to the previous study which indicated that cardiovascular endurance provides athletes with energy to carry out their sporting activities with vigor [17]. Moreover, cardiovascular endurance is a must have component for contribution in any type of sports [18]. It is an important fundamental attribute of athletic performance since the heart controls the oxygen flow to all the working muscles [19]. Therefore, cardiovascular endurance has a strong impact on athlete's performance in various kinds of sports. This finding is related to the previous investigation which reported that cardiovascular fitness improves the ability of the heart and lungs to supply oxygen-rich blood to the working muscles which in turn accelerates the actions of the athletes to act in response to the fitness requirement of the sport he or she participates in [20].

Current finding also revealed second component in PCA consist of anthropometric measurements. Anthropometric have the major advantage of studying the physique of different populations, athlete and non-athletes. There also true evident that measurement of anthropometric variables can create a profile of athlete within specific sports [21]. Since different sports have different anthropometric characteristics, the findings could help coaches to select players for the professional level according with the playing position. Conversely, the finding from PCA discloses that the participant varies from the other participant based on their performance on lower limb strength (sanding broad jump) and upper limb strength (vertical jump).

\section{Conclusion}

This study has applied multivariate methods, namely, the PCA and DA, to study the relative performance variations of the most significant performance elements for selecting the best player among U12. The newly proposed APCI model was developed by using factor score derived by PCA. It has identified three groups based on their anthropometrics and physical fitness performance. These groups are LPG, MPG, and HPG. The finding of this study also revealed a total number of two potential respondents out of 178 through the standard, forward stepwise and backward stepwise method of DA. DA identified three variables (weight, standing broad jump and 40 meter run) that differentiate all the groups. Such variables were established as essential indicator for selecting the best player among male U12. Present finding also implied that the application of multivariate analysis is vital in identifying essential performance parameters in the variety of games which can save time, energy and cost.

\section{Acknowledgement}

The authors would like to thank the Research Management, Innovation and Commercialization Centre, Universiti Sultan Zainal Abidin, Terengganu State Sports Council and National Sports Institute for providing the research grant (i1017-00005) and their support in this research.

\section{References}

[1] Balyi, I., Way, R., \& Higgs, C. (2013). Long-term athlete development. Human Kinetics.

[2] Balyi, I., \& Hamilton, A. (2004). Long-term athlete development: Trainability in childhood and adolescence: Windows of opportunity, optional trainability. Victoria, British Colombia: National Coaching Institute and Advanced Training and Performance.

[3] Papacharisis, V., Goudas, M., Danish, S. J., \& Theodorakis, Y. (2005). The effectiveness of teaching a life skills program in a sport context. Journal of Applied Sport Psychology, 17(3), 247-254.

[4] Jones, M. I., \& Lavallee, D. (2009). Exploring the life skills needs of British adolescent athletes. Psychology of sport and Exercise, 10(1), 159-167

[5] Lang, M., \& Light, R. (2010). Interpreting and implementing the long term athlete development model: English swimming coaches' views on the (swimming) LTAD in practice. International Journal of Sports Science and Coaching, 5(3), 389-402.

[6] Abbott, A., \& Collins, D. (2002). A theoretical and empirical analysis of a'state of the art'talent identification model. High Ability Studies, 13(2), 157-178.

[7] Abbott, A., \& Collins, D. (2004). Eliminating the dichotomy between theory and practice in talent identification and development: Considering the role of psychology. Journal of Sports Sciences, 22(5), 395-408.

[8] G. Hoare, D., \& Warr, C. R. (2000). Talent identification and women's soccer: An Australian experience. Journal of Sports Sciences, 18(9), 751-758.

[9] Maliki, A. B. H. M., Abdullah, M. R., Juahir, H., Abdullah, F., Abdullah, N. A. S., Musa, R. M., Mat-Rasid, S. M., Adnan, A. Kosni, N. A., Muhamad, W. S., \& Nasir, N. A. M. (2018). A multilateral modelling of Youth Soccer Performance Index (YSPI). IOP Conference Series: Materials Science and Engineering, 342(1), $1-10$

[10] Maliki, A. B. H. M., Abdullah, M. R., Juahir, H., Muhamad, W. S. A. W., Nasir, N. A. M., Musa, R. M., Mat-Rasid, S. M., Adnan, A. Kosni, N. A., Abdullah, F., \& Abdullah, N. A. S. (2018). The role of anthropometric, growth and maturity index (AGaMI) influencing youth soccer relative performance. IOP Conference Series: Materials Science and Engineering, 342(1), 1-10.

[11] Abdullah, M. R., Maliki, A. B. H., Musa, R. M., Kosni, N. A., Juahir, H., \& Mohamed, S. B. (2017). Identification and comparative analysis of essential performance indicators in two levels of soccer expertise. International Journal on Advanced Science, Engineering and Information Technology, 7(1), 305-314.

[12] Abdullah, M. R., Maliki, M., Husin, A. B., Musa, R. M., Kosni, N. A., Juahir, H., \& Haque, M. (2016). Multi-hierarchical pattern recognition of athlete's relative performance as a criterion for predicting potential athletes. Journal of Young Pharmacists, 8(4), 463-470.

[13] Musa, R. M., Abdullah, M. R., Maliki, A. B. H. M., Kosni, N. A., \& Haque, M. (2016). The application of principal components analysis to recognize essential physical fitness components among youth development archers of Terengganu, Malaysia. Indian Journal of Science and Technology, 9(44), 1-6.

[14] Eyduran, E., Karakus, K., Karakus, S., \& Ceng1z, F. (2009). Usage of factor scores for determining relationships among body weight and some body measurements. Bulgarian Journal of Agricultural Science, 15(4), 374-378.

[15] Yakubu, A., Kuje, D., \& Okpeku, M. (2009). Principal components as measures of size and shape in Nigerian indigenous chickens. Thai Journal of Agricultural Science, 42(3), 167-176.

[16] Ifeanyichukwu, U. (2012). Use of factor scores for determining the relationship between body measurements and semen traits of cocks. Open Journal of Animal Sciences, 2(1), 41-44.

[17] Stangier, C., Abel, T., Mierau, J., Hollmann, W., \& Strüder, H. K. (2016). Effects of cycling versus running training on sprint and endurance capacity in inline speed skating. Journal of Sports Science and Medicine, 15(1), 41

[18] Ford, P., De Ste Croix, M., Lloyd, R., Meyers, R., Moosavi, M., Oliver, J \& Williams, C. (2011). The long-term athlete development model: Physiological evidence and application. Journal of Sports Sciences, 29(4), 389-402.

[19] Miyamoto, T., Kamada, H., Tamaki, A., \& Moritani, T. (2016). Low-intensity electrical muscle stimulation induces significant increases in muscle strength and cardiorespiratory fitness. European Journal of Sport Science, 16(8), 1104-1110.

[20] Fenton, S. A., Duda, J. L., \& Barrett, T. (2016). Inter-participant variability in daily physical activity and sedentary time among male 
youth sport footballers: Independent associations with indicators of adiposity and cardiorespiratory fitness. Journal of Sports Sciences, 34(3), 239-251.

[21] Popovici, I. M., Popescu, L., \& Radu, L. E. (2016). Evaluation of some physical fitness characteristics at age 11 to 13. Timisoara Physical Education and Rehabilitation Journal, 9(17), 24-28. 